\title{
COMO O MICROCRÉDITO CONTRIBUI PARA O DESENVOLVIMENTO DAS MPES? ESTUDO MULTICASOS EM EMPRESAS PARTICIPANTES DO APL DE CONFECÇÃO DE SERGIPE
}

\author{
HOW THE MICRO CREDIT CONTRIBUTES TO DEVELOP SMALL AND MICRO \\ BUSINESSES? A MULTICASE STUDY WITH CLOTHES COMPANIES WHICH \\ PARTICIPATE IN THE LOCAL PRODUCTIVE ARRANGEMENTS (LPA) IN THE STATE \\ OF SERGIPE
}

Recebido em 10.02.2013. Aprovado em 10.09.2013

Avaliado pelo sistema double blind review

DOI:http://dx.doi.org/10.12712/rpca.v7i3.260

\begin{abstract}
Cassio Roberto Conceição Menezes
cassiomenezes.32@gmail.com

Programa de Pós-Graduação em Administração da Universidade Federal de Sergipe (PROPADM/UFS) - UFS São Cristóvão - SE - Brasil
\end{abstract}

\section{Abimael Magno do Ouro Filho}

abimaelmagno@hotmail.com

Programa de Pós-Graduação em Administração da Universidade Federal de Sergipe (PROPADM/UFS) - UFS São Cristóvão - SE - Brasil

\section{José Ricardo de Santana}

santana_josericardo@yahoo.com.br

Programa de Pós-Graduação em Administração da Universidade Federal de Sergipe (PROPADM/UFS) UFS - São Cristóvão - SE - Brasil

\section{Resumo}

O objetivo deste artigo é analisar como o microcrédito tem contribuído para o desenvolvimento das micro e pequenas empresas (MPEs), particularmente, aquelas instaladas nos arranjos produtivos locais (APLs) de Itabaianinha e Tobias Barreto (SE). Para tanto, o estudo se caracteriza como exploratóriodescritivo e o método de pesquisa foi o estudo de casos múltiplos. Os principais resultados indicam que o microcrédito tem sido uma importante estratégia financeira das MPEs como capital de giro e investimento. Observou-se também que o fato de as empresas estarem localizadas em um arranjo produtivo tem facilitado o acesso às instituições financeiras e, consequentemente, ao capital solicitado. Os resultados mostram ainda que o microcrédito tem refletido positivamente na expansão das atividades e no aumento das vendas dos empreendedores locais.

Palavras-chave: Microcrédito. Desenvolvimento. Micro e Pequena Empresa.

\section{Abstract}

The purpose of this article is to analyze how microcredit has contributed to the development of micro and small enterprises (MSEs), particularly those installed in local productive arrangements (LPAs) of Itabaianinha and Tobias Barreto (SE). Therefore, the study is characterized as exploratory and descriptive and the researching method was the study of multiple cases. The main results indicate/show that microcredit has been an important financial strategy of MSEs used in working capital and capital of investment. There was also observation of the fact that companies located in a productive arrangement has facilitated access to financial institutions and consequently to the capital required. Results also show that microfinance has influenced positively on the expansion of activities and has increased sales of local entrepreneurs. 
Keywords: Microcredit. Development. Small and Micro Business.

\section{Introdução}

As micro e pequenas empresas têm se destacado no cenário mundial em função da sua participação em diversos setores produtivos, na capacidade de adaptação, dentre outros aspectos. No Brasil, elas representam a maioria das organizações, segundo o porte, e são intensivas em mão de obra. Em 2011, mais de 99\% das empresas formais pertenciam ao agrupamento das micro e pequenas empresas (MPEs) e empregavam mais de $62 \%$ da força de trabalho. No estado de Sergipe a situação não é diferente, uma vez que 98,72\% das empresas em operação são classificadas como MPEs (SEBRAE, 2009).

Apesar do destaque dado às MPEs, verifica-se que este agrupamento empresarial tem sofrido com a abertura dos mercados devido a sua estrutura limitada e à carência de múltiplos recursos (OLIVERIA, 2010), em especial, àqueles que demandam soluções financeiras (OLIVEIRA JUNIOR; CASTRO, 2008) para investimento em produtos e processos. A falta de recursos financeiros na empresa é um dos determinantes apontados pela literatura como fator capaz de comprometer a sua sobrevivência.

Estudo realizado pelo SEBRAE (2007) revela que um dos principais motivos para a falência da micro, pequena e média empresa (MPMEs) é a dificuldade do acesso ao crédito. Outro trabalho (SEBRAE, 2011), mostra que 27,7\% das empresas brasileiras não sobrevivem sequer aos dois primeiros anos de vida. Em Sergipe essa taxa se elava para $32 \%$ se figurando bem acima do índice nacional.

Para se contrapor a tais dificuldades, duas estratégias se apresentam de forma iminente para MPEs: a organização em rede e o microcrédito. Segundo Verschoore (2006), a situação da economia atual demanda novas estruturas organizacionais, mais apropriadas para as necessidades das pequenas empresas. E, dentre as principais formas existentes estão distritos industriais, joint ventures, alianças estratégicas, clusters, arranjos produtivos locais (APL), entre outros. Os APLs propiciam o desenvolvimento das MPMEs e de regiões como um todo ajudandoas, conforme sugere Cassiolatto e Lastres (2001), a superarem barreiras ao crescimento.

Em se tratando de superação, o microcrédito aparece como um importante instrumento desenvolvido para atender as necessidades das MPEs, levando em consideração as condições econômicas e as relações sociais do empresário que deseja tomar o empréstimo. 0 microcrédito tem ainda como objetivo estimular a atividade produtiva, visto que contribui para gerar ocupação, emprego e renda (SEBRAE, 2012a). Assim sendo, o microcrédito também promove o desenvolvimento econômico, cultural e social, influenciando as pessoas a buscarem melhorias (QUICK, 2003), que impactarão tanto na sua qualidade de vida quanto no desenvolvimento de determinadas regiões. 0 aspecto financeiro permanece assim um dos elementos relevantes de investigação no estudo das MPEs.

O presente artigo objetiva analisar como o microcrédito, enquanto produto das microfinanças, tem contribuído para o desenvolvimento das MPEs, particularmente, aquelas instaladas nos APLs de Itabaianinha e Tobias Barreto (SE). De maneira particular, pretende-se, a partir de estudos de caso, analisar: a) as motivações que levaram os empreendedores das MPEs a recorrerem ao microcrédito como estratégia financeira; b) as facilidades de acesso ao microcrédito, observando como condicionante o fato de essas MPEs fazerem parte de um APL, e c) apresentar os principais efeitos percebidos nas empresas, após a obtenção do empréstimo. 


\section{Cassio Roberto Conceição Menezes, Abimael Magno do Ouro Filho e \\ José Ricardo de Santana}

Para tanto, o artigo encontra-se dividido em cinco seções, incluindo esta introdução. A segunda seção trata das abordagens da literatura acerca da Micro e Pequena Empresa, do Arranjo Produtivo Local e do Microcrédito, enfatizando os condicionantes da estratégia financeira das empresas. A terceira, aborda os procedimentos metodológicos na investigação do tema. A quarta, apresenta os principais resultados observados para cada um dos itens específicos mencionados nos objetivos do trabalho. A última seção traz as considerações finais.

\section{Organização das MPEs e condicionantes financeiros}

As micro e pequenas empresas (MPEs) têm sido um importante objeto de estudo na literatura acadêmica de Administração. Um dos pontos centrais de estudo está na investigação acerca dos fatores que condicionam o desempenho delas. Nesse sentido, ganham destaque as análises sobre a forma de organização das MPEs e as suas estratégias financeiras.

\section{Micro e Pequenas Empresas e seus condicionantes de desempenho}

As micro e pequenas empresas (MPEs) possuem algumas peculiaridades relacionadas à definição, aos impactos econômicos e aos condicionantes. Em relação ao primeiro ponto, Teixeira e Barbosa (2002) dizem que é importante existir uma definição de MPEs, não apenas para caráter formal, mas para que as normas de estímulo à iniciativa privada levem em consideração as diferentes características entre micro, pequenas, médias e grandes empresas. Entretanto, a classificação entre os tamanhos das empresas parece não haver um consenso.

A micro e pequena empresa pode ser classificada tanto pelo número de empregados quanto pelo faturamento anual (SEBRAE, 2012b). Tomando como base classificatória a mão de obra ocupada, sugere-se que a microempresa deve possuir até 19 empregados, se atuar no segmento da indústria, e até 09 pessoas empregadas, se operar no segmento de comércio ou de serviços. Por outro lado, a empresa de pequeno porte que atua no setor industrial deve possuir entre 20 e 99 pessoas empregadas e de 10 a 49 pessoas ocupadas, se pertencer ao setor de comércio e serviços. Em relação ao seu faturamento, as microempresas são aquelas com receita bruta igual ou inferior a $\mathrm{R} \$ 240.000,00$ (duzentos e quarenta mil reais) e a pequena empresa, a receita bruta deve ser superior a $\mathrm{R} \$ 240.000,00$ (duzentos e quarenta mil reais) e igual ou inferior a $\mathrm{R} \$$ 2.400.000,00 (dois milhões e quatrocentos mil reais).

No que se refere aos impactos econômicos, o papel das micro e pequenas empresas (MPEs) como propulsoras do desenvolvimento tem sido destacado na literatura. Segundo Olave e Amato Neto (2001), a pequena empresa se faz importante para a economia por gerar ou contribuir para a produção industrial. Da mesma forma Jiang e Li (2010) relatam que essa classe de empresas é relevante para o desenvolvimento sócio econômico, pois aumentam a renda nacional e proporcionam receita de impostos e empregos.

Em relação aos condicionantes das MPEs, Camargos et al. (2008) evidenciam que as principais vantagens desse nicho empresarial (MPE) estão relacionadas a fatores como: i) facilidade de constituição e entrada no mercado; necessidade de pouco volume de capital inicial; ii) registros e demais trâmites burocráticos de abertura cada vez mais facilitados pelos órgãos governamentais; iii) flexibilidade de gestão e de produtividade. Já as suas desvantagens associam-se aos seguintes elementos: i) presença de gestão amadora, baseada apenas no empirismo e em experiências anteriores, o que compromete o seu crescimento devido à falta de visão de negócios; ii) ausência de um planejamento estratégico; e iii) falta de acesso ao crédito, dificultado, inclusive, por exigências e condições inibidoras. 


\section{COMO O MICROCRÉDITO CONTRIBUI PARA O DESENVOLVIMENTO DAS MPES? ESTUDO MULTICASOS EM EMPRESAS PARTICIPANTES DO APL DE CONFECÇÃO DE SERGIPE}

Consequentemente, a falta de acesso ao crédito tem se constituído um fator limitador de crescimento e desenvolvimento das empresas de menor tamanho (ZICA; MARTINS; CHAVES, 2008; OLIVEIRA; ROCHA, 2005) e, por sua vez, um dos maiores problemas para dar continuidade a esse tipo de empresa é a ausência de recursos financeiros (BRAGA; NOSSA; MARQUES, 2004). Em vista disso, o APL se apresenta com um meio para que as MPEs tenham uma maior facilidade na obtenção de crédito.

\section{Organização de MPEs em Arranjos Produtivos Locais}

Os arranjos produtivos locais (APL) se configuram como uma nova forma de organização produtiva capaz de gerar externalidades positivas e ganhos de eficiência coletiva para enfrentar as limitações comportamentais e organizacionais impostas às micro e pequenas empresas. É uma estratégia relevante paras MPEs que visam a melhoria da sua performance.

Lastres (2002) conceitua o APL como sendo uma aglomeração territorial de agentes econômicos, políticos e sociais, com um conjunto específico de atividades econômicas e que apresentam vínculos e interdependência. Geralmente, envolve a participação e a interação de empresas e suas variadas formas de representação e associação, incluindo também, outras instituições públicas e privadas com o objetivo de: formar e capacitar os recursos humanos, com escolas técnicas e universidades; pesquisa, desenvolvimento e engenharia; política, promoção e financiamento.

Colaborando com a literatura Castro (2009) reconhece que os APLs são marcados pelo significativo número de empresas especializadas em uma produção (setor) e localizadas em uma região (município, parte de um município, conjunto de municípios, etc.) as quais mantêm algum vínculo de articulação, interação, cooperação e aprendizagem entre si e com outros atores locais (governo, associações, instituições de apoio, pesquisa e ensino).

Dentro desse formato organizacional, a cooperação é considerada um fator muito importante (SANTOS; DINIZ; BARBOSA, 2006), pois, quando uma empresa se organiza em rede, elas alcançam maior competitividade no mercado por meio de relacionamentos complexos (BALESTRIN; VARGAS, 2004) que se estabelecem entre as firmas.

Quandt (2012) realizou estudo no arranjo produtivo local de malharias de Imbituva, no Estado do Paraná. Verificou que a cooperação desenvolvida entre as empresas do arranjo compreendiam vínculos relacionados ao compartilhamento de equipamentos ou instalações. 0 estudo revelou a existência de um núcleo de empresas que cooperam de forma bastante intensa, com diversos vínculos de reciprocidade.

Menezes (2013) desenvolveu pesquisa no APL de Confecções de Itabaianinha/SE, com o objetivo de analisar as ações de cooperação quem promovem a geração e difusão de conhecimento no âmbito do arranjo. Os principais resultados indicaram que as ações de cooperação contemplam o compartilhamento de serviços, compra conjunta de tecidos e aviamentos, compra conjunta de softwares e de uma máquina de ploter, o melhoramento do processo produtivo e a troca de informações. Tais ações permitiram a formação e o fortalecimento de uma rede de relacionamento entre as empresas do APL, promovendo externalidades positivas sustentadas pela cooperação e processos de aprendizagem, envolvendo clientes, fornecedores, concorrentes e instituições de apoio.

Ao cooperar com outras empresas, as organizações obtêm vantagens que dificilmente adquiririam agindo de forma isolada, sobretudo no caso das MPEs. Dentre os principais 


\section{Cassio Roberto Conceição Menezes, Abimael Magno do Ouro Filho e \\ José Ricardo de Santana}

benefícios da cooperação, Krugman (1991) destaca: i) a existência de mão de obra especializada: um número de empresas aglomeradas aumenta a possibilidade de existir um agrupamento de mão de obra especializada no mesmo lugar; ii) a existência de fornecedores e prestadores de serviços especializados, o que possibilita a entrada de grande variedade de indústrias a baixo custo; iii) a existência de spillovers tecnológicos e de conhecimento: por estarem concentradas em um só lugar a informação flui mais fácil do que se estivessem separadas.

Para Souza e Gomes (2005) os principais benefícios da cooperação em um APL podem ser percebidos através dos seguintes aspectos: i) redução de custos; ii) aumento do poder de negociação com fornecedores; iii) desenvolvimento de pesquisas; iv) inserção em novos mercados; iv) lançamentos de novos produtos; v) acesso a matéria-prima; vi) acesso a tecnologias; e vii) acesso a financiamentos, dentre outros.

Apesar dos benefícios da cooperação, alguns estudos (CORAZZA; CHAVES, 2010; OURO FILHO, 2013) sobre Arranjos Produtivos Locais desenvolvidos no país têm demonstrado baixo nível de cooperação entre as empresas aglomeradas e grande dificuldade das empresas de pequeno porte em se articular com o mercado formal de crédito.

Iacono e Nagano (2010), por exemplo, realizaram estudo no arranjo produtivo local de equipamentos e implementos agrícolas do oeste do Paraná. Os principais resultados do estudo revelaram que as altas taxas de juros praticadas pelas instituições financeiras e o baixo montante disponibilizado às empresas são os principais obstáculos à cooperação. E, mesmo com um número significativo de instituições financeiras presentes no APL, o acesso aos recursos necessários são limitados e, na maioria das vezes atendem parcialmente às necessidades das empresas localizadas.

$\mathrm{Na}$ tentativa de resolver o problema da quantidade insuficiente de crédito disponível para as organizações de pequeno porte, Mytelka (2002) propôs a criação de um banco orientado para o arranjo produtivo, cuja característica principal é a de oferecer serviços financeiros a baixo custo devido à reduzida assimetria de informações, proporcionada pela proximidade existente entre 0 agente financeiro e as empresas de pequeno porte.

No caso do efeito financeiro dessas organizações, Abramovay (2003) sugere que o acesso ao crédito por empresas aglomeradas deve se dá em função das chamadas finanças de proximidade. Empresas que empreendem finanças de proximidade convertem as relações sociais entre os indivíduos, organizações e instituições em redução de custo de transação. Por conseguinte, acredita-se que as agências adequadas para empreender as finanças de proximidades em APLs são as instituições financeiras locais, tais como, as cooperativas de crédito e as instituições de microcrédito (FERREIRA JUNIOR; SORGATO, 2007). As cooperativas de crédito, quando hospedadas neste tipo de aglomerado atuam como um cluster bank, assegurando as condições de articulação entre o APL, as empresas e o mercado e, promovendo o desenvolvimento sustentável desse segmento empresarial.

Em Sergipe, verifica-se que os arranjos produtivos locais, em geral, interagem com algumas instituições financeiras, principalmente, com o Banco do Nordeste do Brasil (BNB), o Banco do Estado de Sergipe (BANESE), bem como, com o Banco do Brasil - BB (HANSEN et al., 2009).

Nesse contexto, é possível inferir que quanto maior for o nível da interação entre os atores pertencentes ao APL, maior será a facilidade para as empresas obterem financiamento junto às 
instituições de crédito.

\section{Microcrédito como estratégia financeira de MPEs}

Uma das mais importantes fontes de crédito para MPEs, sobretudo quando estas não podem oferecer garantias reais, é o microcrédito. Conceitualmente, o microcrédito é compreendido como empréstimos de valores baixos a pequenas empresas informais e, em geral, a empresas que não tem acesso ao sistema financeiro tradicional, devido à falta de informação e garantias (BARONE et al., 2002). Na percepção de Sela, Sela e Costa (2006), o microcrédito possibilita a geração de emprego e renda para as pessoas com dificuldade de acesso ao crédito tradicional. Essa importância cedida financia a pequena empresa e, ao mesmo tempo, fornece condições essenciais para que as pessoas possuam recursos financeiros mínimos.

Silveira Filho (2005) afirma que o sistema de crédito tradicional está baseado na agência, onde para conceder o crédito é necessário averiguar as normas, burocracias e procedimentos para o empréstimo. Entretanto, o microcrédito está fundamentado no agente de crédito e na sua capacidade de avaliação do cliente. Pois, o agente para conceder o microcrédito não exige as mesmas garantias reais como em um crédito tradicional. Para emprestar, alguns agentes financeiros utilizam o aval solidário (o grupo assume a responsabilidade pelo crédito como uma das garantias), em outros casos, é solicitada a apresentação de um avalista. No Brasil, o microcrédito tem como público alvo as pequenas empresas (PASSOS et al., 2002) e visa o apoio financeiro para tornar o negócio viável e ativo (BRAGA; TONETO, 1999).

Monzoni (2006) classifica o microcrédito em três tipos: i) microcrédito tradicional; ii) microcrédito produtivo; e iii) microcrédito produtivo orientado. 0 primeiro tem como finalidade o serviço de crédito para a população de baixa renda. 0 segundo tem como objetivo oferecer crédito de pequenos valores para as empresas. E o terceiro se caracteriza como o serviço de crédito para as empresas, embasado na relação entre a instituição de microcrédito e o empreendedor, através dos agentes de crédito. O SEBRAE (2012b) indica que as principais características dos financiamentos de microcrédito são:

a) As garantias exigidas pelas instituições de microcrédito são mais simples e de acordo com as condições dos pequenos empreendimentos.

b) As formas mais praticadas são: aval solidário (grupo de pessoas que toma o crédito e assume, conjuntamente, a responsabilidade pelo mesmo como uma das garantias) e o aval individual, esse geralmente representado por um avalista ou pessoa conhecida.

c) Solicitações de garantias reais (patrimônio) são raras.

d) 0 microcrédito é voltado ao financiamento das atividades produtivas dos pequenos empreendedores e raramente financia o consumo.

e) A quantia do financiamento é compatível com as necessidades do negócio e a sua capacidade de pagamento, contudo, nas renovações de crédito os valores podem ser acrescidos.

f) As taxas de juros geralmente são as praticadas no mercado.

g) Os prazos de pagamento geralmente são curtos e sempre ligados à finalidade do financiamento e ao fluxo de caixa da atividade empresarial. Entretanto, existem os casos de investimentos em máquinas, em que os prazos poderão ser mais longos na medida da capacidade de retorno financeiro do investimento.

h) Caracteriza-se como sendo um tipo de crédito rápido, possibilitando ao cliente o aproveitamento da oportunidade de negócio.

i) 0 microcrédito é caracterizado pela simplicidade e agilidade na análise, aprovação e liberação dos recursos.

j) Regularmente, o agente de crédito visita o empreendimento financiado e acompanha a aplicação dos recursos e o desenvolvimento do negócio. 
Desse modo, existem três justificativas que sustentam a consolidação do microcrédito: 1) Há uma grande quantidade de empresas formais e informais de pequeno porte; 2) o aumento no número do desemprego; e 3) dificuldades de acesso ao crédito tradicional (SANTOS, 2006). Ainda de acordo com o mesmo autor, o microcrédito pode gerar um ambiente econômico favorável às empresas, suprindo a sua necessidade de crédito e, paralelamente, possibilitando a geração de emprego e renda.

Para Yunus (2002), o acesso ao crédito produtivo possibilita que as pessoas excluídas do circuito financeiro tradicional possam desenvolver melhores condições socioeconômicas, com dinamização de seus pequenos empreendimentos. Oliveira e Silva (2012) realizaram estudo e caso na CREDITAG em Rondônia, com o objetivo de verificar a eficiência das iniciativas econômicas locais de caráter coletivo. Concluíram que, iniciativas econômicas locais representam uma opção ponderável para os segmentos sociais de baixa renda, fortemente atingidos pelo quadro de desocupação estrutural e pelo empobrecimento. Indicam, portanto, que esse é um caminho viável para a promoção do desenvolvimento econômico e social.

Diante do exposto, mostra-se relevante investigar se a estratégia financeira das MPEs, consolidada no uso do microcrédito, tem contribuído para o seu desenvolvimento, com ênfase nas empresas que fazem parte de APLs.

\section{Procedimentos metodológicos de investigação}

A investigação sobre a estratégia financeira das MPEs, observando as suas motivações, condições de acesso e os efeitos da operação, foi realizada a partir de estudos de casos múltiplos no APL de confecções em Sergipe. A metodologia e descrição das empresas são apresentadas nos itens abaixo.

\section{Metodologia de análise dos efeitos do microcrédito sobre MPEs}

A análise de dados foi realizada a partir de um estudo exploratório-descritivo, com análise de casos múltiplos, envolvendo inicialmente três empresas, todas pertencentes ao setor de confecção, sendo uma localizada no município de Tobias Barreto e as outras duas em Itabaianinha. Nessas regiões está situado o Arranjo Produtivo Local de confecções de Sergipe. Foram definidas as principais categorias analíticas e os critérios para a escolha dos casos. A partir daí, foram buscadas as fontes de evidências para a realização da pesquisa.

Sobre a característica da investigação, pode-se dizer que estudos exploratórios, segundo Neuman (1997), ocorrem quando o estudo é novo ou quando existe pouca literatura sobre o tema. E podem ser tidos como descritivos aqueles que apresentam um esboço com detalhes específicos de uma situação, configurações sociais ou relações.

O método de pesquisa escolhido foi o estudo de múltiplos casos. A utilização desta metodologia, em geral, vem acompanhada de perguntas do tipo "como" e "por que", pois de acordo com Yin (2005), estas são questões que lidam com ligações operacionais que necessitam ser traçadas ao longo do tempo e, geralmente, são ambivalentes, necessitando de esclarecimentos. Por conseguinte, o autor acredita que estudos de múltiplos casos são mais convincentes e consequentemente mais robustos.

Para a realização da investigação, algumas categorias analíticas foram estabelecidas, a saber: i) motivações que levaram os empreendedores a recorrerem ao microcrédito e valor do empréstimo tomado; i) facilidades de acesso ao empréstimo; e iii) mudanças percebidas no 
negócio.

Os critérios adotados para a escolha dos casos foram:

(1) ser micro ou pequena empresa;

(2) pertencer ao setor de confecção;

(3) estar inserida em APL;

(4) ter obtido algum empréstimo do tipo microcrédito nos últimos dois anos.

Em relação às fontes de evidências, Yin (2005) enumera seis tipos principais: i) documentos; ii) registros em arquivos; iii) observação direta; iv) participante; v) artefatos físicos; e vi) entrevistas. Para os casos estudados, foram utilizadas a documentação, a entrevista e também a pesquisa bibliográfica. Em seguida, foi feita a triangulação dos dados como forma de obter informações variadas e dar maior credibilidade à pesquisa realizada.

Para análise dos dados foi utilizada a técnica de análise de conteúdo. Segundo Flick (2009), este é um procedimento para se analisar o material textual independente da sua origem. Feito isso, alguns depoimentos dos entrevistados foram selecionado e apresentados na íntegra na análise comparativa dos dados.

\section{Caracterização das empresas que compuseram o estudo e dos seus empreendedores}

A análise de conteúdo foi realizada a partir dos casos de três empresas do setor de confecção, sendo uma localizada no município de Tobias Barreto e, as outras duas, em Itabaianinha. Nessa região sergipana está situado o Arranjo Produtivo Local de confecções.

O Quadro 1 mostra as características das empresas estudadas quanto ao ramo de atividade, tempo de atuação no mercado e número de empregados. Dos três estabelecimentos pesquisados, dois são formais e estão localizados no APL de Itabaianinha/ SE, o terceiro pertence ao APL de Tobias Barreto e opera na informalidade.

Quadro 1 - Características das empresas.

\begin{tabular}{|c|c|c|c|c|c|}
\hline \multirow{4}{*}{ 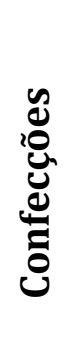 } & Empresa & $\begin{array}{l}\text { Ramo de } \\
\text { atividade }\end{array}$ & $\begin{array}{c}\text { Tempo de atuação } \\
\text { no mercado }\end{array}$ & $\begin{array}{l}\text { Número de } \\
\text { empregados }\end{array}$ & Localização \\
\hline & Alfa & Ind. e Comércio & 8 anos & 12 & Itabaianinha \\
\hline & Beta & Ind. e Comércio & 3 anos & 10 & Itabaianinha \\
\hline & Gama & Com.varejista & 9 anos & 1 & Tobias Barreto \\
\hline
\end{tabular}

Fonte: Elaborado pelos autores.

Tomando por base a classificação estabelecida pelo SEBRAE (2012b) em relação ao porte das organizações, verifica-se que todas as firmas que compõem o estudo são microempresas, pois possuem de um a doze empregados.

Quanto ao tempo de atuação no mercado, o SEBRAE (2011) revela que os dois primeiros anos de atividade de uma nova empresa são os mais difíceis, podendo implicar em sua mortalidade ou continuidade, o que torna esse período o mais importante em termos de monitoramento da 
sobrevivência. Como se pode perceber, o tempo de vida das empresas estudadas ultrapassa o período considerado crítico e, paralelamente, indica que estas organizações estão passando por uma fase de maturação.

Todos os entrevistados possuem idade entre dezoito e trinta e cinco anos. O da ALFA é estudante de administração, o outro da BETA é formado em pedagogia, e um terceiro da GAMA não conseguiu concluir o ensino fundamental. Os dois primeiros relataram que antes de abrir a empresa trabalhavam no mesmo ramo de atividade, embora na qualidade de empregado. Por sua vez, decidiram abrir o seu próprio negócio após o fechamento da fábrica em que laboravam. Logo, parece que a motivação desses empresários para empreender está associada ao desemprego. No entanto, o empreendedor do caso GAMA declarou ter percebido uma oportunidade de trabalho, pois faz parte de uma Igreja Evangélica e observou que havia ali uma grande demanda por ternos. Desde então, iniciou a comercialização desse produto.

\section{Análise comparativa dos casos}

Os casos em estudo foram analisados considerando as categorias analíticas escolhidas para verificação e, portanto, buscam responder a três questões: 1) quais as motivações que levaram os empreendedores a recorrerem ao microcrédito como estratégia de financiamento; 2) quais as condições de acesso ao empréstimo e sua relação com a organização em um APL; e 3) quais as mudanças percebidas no negócio, em termos da performance das empresas.

\section{Quais as motivações que levaram os empreendedores a recorrerem ao microcrédito?}

Nesse quesito buscou-se analisar a estratégia financeira dos empreendedores com foco no microcrédito. Foram observados fatores que, de alguma forma, poderiam estar relacionados à motivação de tomar emprestado o recurso financeiro, tais como abertura da empresa, capital de giro, investimento ou outros fins desconhecidos.

Dos casos estudados, apenas a empreendedora da empresa BETA revelou que o microcrédito vem sendo utilizado para aquisição de matéria-prima, ou seja, para investimento. Tanto os proprietários da empresa ALFA quanto da empresa GAMA afirmaram que o microcrédito estava sendo utilizado para capital de giro. Este último fez a seguinte declaração:

"Você com dinheiro na mão tem voz ativa [...] o preço é outro [...] assim, o capital de giro permite que a gente consiga melhores preços junto aos fornecedores" (EMPRESA GAMA).

Portando, nas três situações apresentadas, é possível inferir que a destinação do microcrédito vem sendo orientada para expansão e manutenção da atividade que está sendo exercida e, em geral, os valores percebidos (ver Quadro 2) variam entre $R \$ 500,00$ e $R \$ 15.000,00$.

Quadro 2 - Motivação para recorrer ao microcrédito e valores percebidos.

\begin{tabular}{|l|l|l|}
\hline Empresa & Motivação para tomar o empréstimo & Valor do empréstimo tomado (R\$) \\
\hline Alfa & Capital de giro & 15.000 \\
\hline Beta & Investimento & Entre 1.501 e 3.000 \\
\hline Gama & Capital de giro & Entre 500 e 1.500 \\
\hline
\end{tabular}

Fonte: Elaborado pelos autores, a partir de pesquisa direta junto às empresas. 
Esse fato corrobora com o estudo de Andreassi (2004), o qual discute a contribuição do microcrédito para o desenvolvimento das empresas. 0 estudo foi realizado junto a 88 empreendedores catarinenses e os principais resultados indicaram que grande parte do crédito recebido é destinada ao financiamento do capital de giro da empresa. Sela, Sela e Costa (2006), entrevistaram 60 clientes do Banco do Povo de Maringá e verificaram que 31,67\% dos entrevistados utilizaram os recursos do microcrédito para o capital de giro e 48,33\% em investimento.

\section{Quais as condições de acesso ao empréstimo?}

A estratégia financeira das empresas pode estar relacionada a condicionantes importantes, como o porte da empresa ou a sua inserção em uma determinada organização, como o fato de fazer parte de um APL. Buscou-se analisar tais condicionantes nos casos em estudo.

A investigação demonstrou que, em Sergipe, aparentemente as instituições financeiras têm "facilitado" o acesso ao crédito para empresas de micro e pequeno porte, especialmente, por meio de políticas pontuais que tentam impulsionar o desenvolvimento dessas organizações. Três instituições foram citadas durante a pesquisa: o Banco do Brasil - BB, o Banco do Estado de Sergipe - BANESE e o Banco do Nordeste do Brasil - BNB. Estas instituições são as mesmas que constam no estudo de Hansen et al. (2009), os quais identificaram que estes bancos mantém forte ligação com as empresas sergipanas instaladas nos arranjos produtivos locais do Estado.

As instituições financeiras trabalham na perspectiva do microcrédito produtivo orientado. Recorrendo a Monzoni (2006), é possível inferir que este tipo de empréstimo caracteriza-se como um serviço de crédito para as empresas, embasado na relação entre a instituição de microcrédito e o empreendedor, através dos agentes de crédito (MONZONI, 2006). Fontes e Pero (2011) enfatizam que o microcrédito surge como uma alternativa para suprir as necessidades do microempreendedores que não têm acesso ao mercado de crédito formal.

Apesar da facilidade de acesso ao recurso, observa-se que, de maneira geral, os valores liberados pelo BNB são baixos (de $\mathrm{R} \$ 500,00$ a $\mathrm{R} \$ 5.000,00$ ) e os prazos são curtos. Os pagamentos são feitos em até quatro vezes e o programa de crédito que esses empreendedores têm maior acesso é o CrediAmigo. Para Buchmann e Neri (2008, p. 3) "o CrediAmigo possui grande parte das características essenciais a um programa de microcrédito bem-sucedido".

Demonstra-se que o alcance desse público-alvo é viabilizado com a adoção dos colaterais substitutos, como o aval solidário e/ou através da metodologia de concessão de crédito baseada na figura do "agente de crédito" responsável pela avaliação presencial das condições de pagamento de cada cliente (FONTES; PERO, 2011).

Assim sendo, os novos formatos contratuais possibilitam a oferta de crédito para aqueles empreendedores tradicionalmente excluídos do mercado financeiro por não terem garantias para o empréstimo. Conforme destaca Corazza e Chaves (2010) em seu estudo sobre o cooperativismo de crédito e empresas de pequeno porte em arranjo produtivo local, a consolidação de novas práticas bancárias amplificam as possibilidades de financiamento.

A presente investigação sugere que dentre as principais exigências apontadas no quadro 3 para adquirir o microcrédito, destacam-se: formação do grupo solidário, documentação pessoal, inexistência de restrições, visitas periódicas dos agentes bancários, comprovante de renda e 


\section{Cassio Roberto Conceição Menezes, Abimael Magno do Ouro Filho e José Ricardo de Santana}

apresentação da mercadoria. Tais exigências revelam uma postura defensiva do sistema bancário, temeroso pela incapacidade das MPEs em garantir um fluxo de rendimentos em suas operações, que seja suficiente para efetuar o pagamento de suas obrigações financeiras (CORAZZA; CHAVES, 2010).

As exigências (ver quadro 3) complementam-se de forma a assegurar que o capital investido pelo banco será pago. Silveira Filho (2005) ressalta que como o microcrédito encontra-se fundamentado no agente de crédito e na sua capacidade de avaliação do cliente, a sua concessão não deve exigir as mesmas garantias reais como em um crédito tradicional.

Quadro 3 - Sergipe: Exigências e garantias para obtenção de crédito

\begin{tabular}{|l|l|}
\hline Instituições Financeiras & Exigências/Garantias \\
\hline BB & $\begin{array}{l}\text { Além da documentação da empresa, pede uma previsão de } \\
\text { faturamento com assinatura de um contador. }\end{array}$ \\
\hline BANESE & Exige apresentação da declaração de imposto de renda - IR. \\
\hline BNB & $\begin{array}{l}\text { Formação de grupo solidário, de no mínimo três pessoas; } \\
\text { documentação pessoal; nome sem restrições; comprovante de } \\
\text { renda; demonstração de mercadoria; envolvimento de agentes de } \\
\text { crédito para avaliação presencial dos clientes. }\end{array}$ \\
\hline
\end{tabular}

Fonte: Elaborado pelos autores.

No caso das empresas analisadas, o proprietário da empresa ALFA solicitou o microcrédito, pela primeira vez, no BB. Ele diz que, ao abrir a conta, o crédito foi concedido. Neste caso específico, o empreendedor conseguiu um crédito de $\mathrm{R} \$ 15.000,00$, que faz parte de uma linha destinada a micro e pequenos negócios. 0 empréstimo tomado pela empresa ALFA é do tipo produtivo, o qual, segundo Monzoni (2006), tem por objetivo oferecer crédito de pequenos valores para as empresas. As operações de empréstimos direcionadas para atividades produtivas em um APL fortalece o potencial do arranjo, tanto espacial quanto ao longo da cadeia de valor.

O prazo para pagamento era em média de vinte e quatro meses e a taxa de juros era atrativa, uma vez que os empreendedores da região experimentavam um momento de crescimento a pleno vapor, como revelou o entrevistado. Indica ainda que, hoje, existem taxas melhores praticadas por outras instituições, a exemplo do Banco do Nordeste. O proprietário da empresa ALFA reconhece dois fatores indispensáveis para o sucesso dessa concessão: o faturamento da empresa e o relacionamento entre o proprietário desta e o gerente da agência bancária.

Já os empreendedores das empresas, BETA e GAMA, demonstraram ter maior interação com o Banco do Nordeste do Brasil, justamente porque as taxas são mais atrativas. Sob este aspecto, a empreendedora BETA comenta que:

"É o melhor juro que a gente viu [...] antes de tomar o empréstimo nós fizemos uma pesquisa nas outras instituições financeiras, mas realmente a taxa de juros praticada pelo BNB é a melhor. E, além do recurso ser liberado rapidamente, eles me oferecem um limite alto para troca de cheques. Eu mesmo estou gostando de trabalhar com o BNB!" (EMPRESA BETA). 
Como as empresas que compuseram o estudo fazem parte de aglomerações produtivas em suas distintas localizações, buscou-se ainda compreender, se o fato delas estarem inseridas em um APL facilitaria o acesso ao crédito. Os resultados sinalizam para proposições diferenciadas:

"Acredito que sim. Quando as empresas se instalaram aqui no polo e iniciaram as suas atividades, todo dia a gente recebia a visita dos gerentes de banco, trazendo uma proposta nova e mostrando as linhas de crédito que eles tinham para as empresas do APL, mas depois da crise..." (EMPREENDEDOR ALFA).

Percebe-se então que, o entrevistado considera que o fato da sua empresa estar instalada no APL tem despertado o interesse das instituições financeiras - IFs, quanto à liberação de crédito. Porém, sinaliza que esse empenho vem diminuindo em função das dificuldades atravessadas pelo setor de confecções nessas cidades do interior do estado: i) mudança de foco das empresas, as quais antes atendiam, prioritariamente, o comércio varejista e agora direcionam os seus esforços no atendimento ao setor industrial, com vendas em atacado; ii) redução no número de visitantes e compradores; iii) falta de competitividade; iv) concorrência acirrada com a entrada de produtos chineses; e v) variedade e preço baixo praticado pelo arranjo locacional do agreste pernambucano.

De acordo com a empreendedora BETA, "se a pessoa está ok, ela obterá recurso em qualquer lugar" e, na percepção do empresário GAMA, as linhas de crédito existem porque fazem parte de políticas de desenvolvimento regional. Ele cita uma cidade próxima do seu município que o comércio é incipiente e, no entanto, as empresas podem desfrutar dos mesmos benefícios, especificamente, aqueles relacionados ao crédito.

Para Souza e Gomes (2005), o fato de as empresas compartilharem das mesmas espacialidades e agirem de forma cooperada traz vantagens que dificilmente elas conseguiriam obter isoladamente, dentre as quais, destacam-se a redução de custos, o aumento do poder barganha, o desenvolvimento de pesquisas, a inserção em novos mercados [...] e o acesso a financiamentos e novas tecnologias. No caso analisado, o acesso ao crédito é fruto da relação de cooperação entre as empresas aglomeradas e as instituições financeiras da região, o que corrobora com os estudos de Corazza e Chaves (2010) que desenvolveram estudos sobre o arranjo produtivo local de confecções de bonés de Apucarana, no Paraná.

Complementarmente, Lastres (2002) revela que as instituições de apoio, certamente, as IFs, objetivam promover o financiamento das empresas aglomeradas. Corroborando os relatos da literatura, os proprietários das empresas entrevistadas, principalmente da ALFA e da GAMA, demonstraram perceber uma atenção diferenciada em função de fazerem parte de um APL.

\section{Quais as principais mudanças percebidas nas empresas após a obtenção do empréstimo?}

0 acesso ao microcrédito, enquanto estratégia financeira, somente terá efetivo sobre a empresa se trouxer mudanças na sua performance. Nesse sentido, a percepção dos empresários pode ser bastante elucidativa.

Ao apresentar essa questão, observamos que os microempresários entrevistados possuem 


\section{Cassio Roberto Conceição Menezes, Abimael Magno do Ouro Filho e \\ José Ricardo de Santana}

visões diferenciadas quanto às mudanças que impactaram no desenvolvimento das suas empresas. Em geral, nota-se que além da expansão do negócio os empreendedores destacam que houve aumento nas vendas e, consequentemente, o fato de ter acesso ao recurso financeiro permitiu a ampliação do mix dos produtos, com aquisição de matéria prima, máquinas e utensílios. Paralelamente, outros resultados são mostrados, conforme detalhamento do Quadro 4.

Quadro 4 - Principais mudanças que impactaram no desenvolvimento das empresas.

\begin{tabular}{|l|l|}
\hline Empresas & Principais Mudanças \\
\hline ALFA & $\begin{array}{l}\text { Adquiriu máquinas, utensílios e matérias primas; e expandiu o } \\
\text { negócio/atividade. }\end{array}$ \\
\hline BETA & $\begin{array}{l}\text { Percebeu aumento nas vendas; adquiriu máquinas e materiais; expandiu o } \\
\text { negócio; melhorou a qualidade do produto e contratou novos funcionários. }\end{array}$ \\
\hline GAMA & Houve aumento nas vendas. \\
\hline
\end{tabular}

Fonte: Elaborado pelos autores.

Isso pode ser verificado na declaração de um entrevistado:

“O microcrédito proporcionou o aumento nas minhas vendas [...], pois quando você tem o produto na loja, você vende mais e com dinheiro em mãos é possível conseguir preços mais baixos" (EMPRESA GAMA).

Depreende-se que a expansão do negócio, apontados pelas empresas ALFA e BETA, se deu tanto pela abertura e manutenção das facções que funcionam nos entorno do polo de confecção quanto pela ampliação da sua demanda e oferta. Nessas facções são confeccionadas parte das peças que são comercializadas nas empresas instaladas no polo.

Esses resultados corroboram, em parte, com o estudo de Sela, Sela e Costa (2006), os quais analisaram a importância do microcrédito para o desenvolvimento econômico e social, bem como as contribuições proporcionadas pelo Banco do Povo de Maringá aos tomadores de microcrédito. As principais constatações dessa pesquisa indicam que o empréstimo permitiu a aquisição de máquinas e utensílios, assim como a expansão de seus negócios, confirmando uma tendência de ampliação da atividade exercida pelo empresário, mediante a aquisição do microcrédito, cujo reflexo se deu no aumento das vendas.

Os pontos de conflitos que surgem da comparação entre este estudo e a investigação realizada por Sela, Sela e Costa (2006), dizem respeito à contratação de novos empregados e à melhoria na qualidade dos produtos e/ou serviços ofertados.

\section{Considerações Finais}

O objetivo principal deste artigo foi o de analisar como o microcrédito tem contribuído para o desenvolvimento das MPEs, em particular, aquelas instaladas nos APLs de Itabaianinha e Tobias Barreto (SE). Os principais resultados indicam que, mesmo formalizadas, as microempresas encontram dificuldades de acesso aos canais tradicionais de financiamento. Essas dificuldades podem estar relacionadas ao nível de exigências e garantias estabelecidas pelas instituições financeiras, o que vem impactando negativamente no desenvolvimento das organizações de porte menores. Mesmo assim, as conexões estabelecidas no aglomerado constituem-se em um 
ativo que produz ganhos econômicos.

Nesse sentido, o microcrédito surge como uma alternativa para elevar o nível de renda e emprego de pessoas carentes. Ao mesmo tempo, aumenta a competitividade das microempresas que se encontram marginalizadas pela falta de acesso ao crédito e, por sua vez, constitui um importante remédio de combate às desigualdades que permeiam o ambiente das organizações.

Verificou-se que o microcrédito tem sido utilizado como estratégia financeira das MPEs no casos estudados. Sua aplicação, em geral, está relacionada a capital de giro e a investimento, em conformidade com o que está relatado em outros estudos da literatura sobre o assunto. Perceptivelmente, os bancos que possuem taxas de juros mais atrativas, também são aqueles que mais facilitam o acesso ao microcrédito. Na concepção de Sela, Sela e Costa (2006), o microcrédito surge como uma ferramenta para o desenvolvimento dos negócios, uma vez que apresenta menores taxas de juros, servindo, assim, como uma opção mais viável em termos de custos.

Os resultados apontam ainda que o fato de as empresas estarem localizadas em um arranjo produtivo tem facilitado o acesso às instituições financeiras e, consequentemente, ao recurso financeiro do microcrédito, que tem menores exigências de garantias reais, quando comparado aos instrumentos financeiros tradicionais. Esse é um outro achado que corrobora com os relatos da literatura, onde são destacadas as melhores condições obtidas por empresas situadas em uma organização especial.

Por fim, deve-se destacar ainda os efeitos positivos sobre a empresa decorrentes da utilização do microcrédito. Nos casos estudados, isso ocorre, principalmente, na expansão do negócio e no aumento das vendas. Contudo, pesquisas futuras poderão indicar os efeitos não captados nos casos em análise, alargando o campo de conhecimento sobre o assunto em estudo. Como limitação deste trabalho, podemos destacar a escassez de literatura que aborda essa temática; a dificuldade de acesso aos empreendedores; e a dificuldade de generalizações.

\section{Nota}

Para ser enquadrada como microempresa a organização deve ter até dezenove pessoas ocupadas, quando atuar no setor industrial, e até nove empregados, se operar no segmento de comércio ou de serviços SEBRAE (2012b).

\section{Referências}

ABRAMOVAY, R. Finanças de proximidade e desenvolvimento territorial no semi-árido brasileiro. In: COSSÍO, Maurício Blanco (Org.). Estrutura agrária, mercado de trabalho e pobreza rural no Brasil. 2003. Disponível em: http://www.econ.fea.usp.br/abramovay/artigos cientificos.htm . Acesso em: 18 jul. 2012.

ANDREASSI, Tales. Impactos do microcrédito junto ao empreendedor de pequenos negócios: o caso do Bancri/SC. Administração em Diálogo, São Paulo, n. 6, p. 75-85, 2004.

BALESTRIN, A.; VARGAS, L. M. A Dimensão Estratégica das Redes Horizontais de PME's: Teorizações e evidências. Revista de Administração Contemporânea, Curitiba-PR, v. 8, ed. Especial, 2004.

BARONE, F. M.; LIMA, P. F.; DANTAS, V.; RESENDE, V. Introdução ao microcrédito. Brasília: Conselho da Comunidade Solidária, 2002. 
BRAGA, R.; NOSSA, V.; MARQUES, J.A.V.C. Uma proposta para a análise integrada da liquidez e rentabilidade das empresas. Revista Contabilidade \& Finanças, edição especial, p. 51-64, 2004.

BRAGA, M. B.; TONETO, J. R. Microcrédito Aspectos Teóricos e Perspectiva. Informações FIPE, São Paulo, n. 226, 1999.

BUCHMANN, Gabriel; NERI, Marcelo Côrtes. O Grameen brasileiro Avaliação do Desempenho Econômico dos Clientes do CrediAmigo. In.: Encontro Nacional de Economia, 36. 2008, Salvador. Anais... Salvador, 2008.

CASTRO, L. H. Arranjo produtivo local. Brasília: SEBRAE, 2009.

CAMARGOS, M. A; CAMARGOS, M. C; SILVA, F. W; RODRIGUES, P. J. Levantamento dos fatores condicionantes de inadimplência em processo de concessão de credito a micro e pequenas empresas do estado de Minas Gerais. CEDEPLAR-UFMG, 2008.

CASSIOLATO, J. E.; LASTRES, H. M. M. Arranjos e sistemas produtivos locais na indústria brasileira. Revista de Economia Contemporânea, Rio de Janeiro, v. 5, ed. esp., p. 103-136, 2001.

CORAZZA, Gentil; CHAVES, Sidney Soares. Cooperativismo de crédito e empresas de pequeno porte em arranjo produtivo local: o estudo de caso do APL de confecções de bonés de Apucarana/PR. A Economia em Revista, vol. 18, n. 2, p. 21-36, dez. 2010.

FLICK, U. Introdução à pesquisa qualitativa. (J. E. Costa, Trad.). São Paulo: Artmed, 3ำ ed., 2009.

FERREIRA JUNIOR., R. R.; SORGATO, L. A. A. vazamento de crédito no Nordeste e uma proposta de sistema de financiamento local: o caso de Alagoas. Economia política do desenvolvimento, Maceió, vol. 1, n. 1, p. 33-63, jan./abr. 2007.

FONTES, Adriana; PERO, Valéria. Desempenho dos Microempreendedores no Brasil. Revista Economia, Brasília, v.12, n.3, p.635-665, set/dez. 2011.

HANSEN, D. L., MELO, R. O. L., LIMA, R. R. P., OLIVEIRA, M. S., JESUS, D. S. de. Caracterização, Análise e Sugestões para Adensamento das Políticas de Apoio a APLs Implementadas nos Estados. NT 05 Projeto Análise do Mapeamento e das Políticas para Arranjos Produtivos Locais no Norte, Nordeste e Mato Grosso e dos Impactos dos Grandes Projetos Federais no Nordeste. RedeSist, IE/UFRJ/BNDES, 2009.

IACONO, Antônio; NAGANO, Marcelo Seido. Cooperação, Interação e Aprendizagem no Arranjo Produtivo Local de Equipamentos e Implementos Agrícolas do Paraná. Interações, v. 11, n. 2, p. 171-185, jul./dez. 2010.

JIANG, L.; LI, X. Discussions on the Improvement of the Internal Control in SMEs. International Journal of Business and Management, v. 5, n. 9, 2010.

KRUGMAN, P. Geography and Trade. Cambridge, MA: MIT Press, 1991.

LASTRES, H. M. M. et al. Interagir para competir: promoção de arranjos produtivos e inovativos no Brasil. Brasília: SEBRAE, 2002.

MENEZES, Cassio Roberto C. de. Geração e Difusão de Conhecimento: uma análise do arranjo produtivo local de confecções de Itabaianinha/ SE, 2013. 120 f. Dissertação (Mestrado) Programa de Pós-Graduação e Pesquisa em Administração, Universidade Federal de Sergipe, São Cristóvão, 2013. 


\section{COMO O MICROCRÉDITO CONTRIBUI PARA O DESENVOLVIMENTO DAS MPES? ESTUDO MULTICASOS EM EMPRESAS PARTICIPANTES DO APL DE CONFECÇÃO DE SERGIPE}

MONZONI NETO, Mário Prestes. Impacto em renda do microcrédito. Tese de Doutorado em Administração Pública e Governo. 1996. Escola de Administração de Empresas de São Paulo. São Paulo: Fundação Getúlio Vargas, 1996. 194 f.

MYTELKA, L.K. Uma nova iniciativa para fortalecer as economias locais: o banco de arranjos produtivos. In: LASTRES, H.M.M. et al (orgs). Interagir para competir: promoção de arranjos produtivos e inovativos no Brasil. Brasília: SEBRAE: FINEP; CNPq, 2002.

NEUMAN, L. W. Social Research Methods: Qualitative and Quantitative Approaches. 3. ed. Boston: Allyn\& Bacon, 1997.

OLAVE, Maria Elena Leon; AMATO NETO, João. Redes de cooperação produtiva: uma estratégia de competitividade e sobrevivência para pequenas e medias empresas. Gestão e Produção, v.8, n.3, p. 289-303, dez. 2001.

OLIVEIRA, M. F. Análise da estrutura de relacionamento em redes de MPEs: um estudo de empresas na Serra do Cipó - MG. Dissertação do Mestrado em Administração da Universidade FUMEC, na área de concentração de Gestão Estratégica de Organizações, 2010.

OLIVEIRA, Nilza Duarte Aleixo de; SILVA, Tânia Nunes. Iniciativas Econômicas Locais como Forma de Promover o Desenvolvimento Sustentável: o caso CREDITAG em Rondônia. Revista de Administração e Negócios da Amazônia, v. 4, n. 3, set./dez. 2012.

OLIVEIRA, U. R.; ROCHA, H. M. Estudos de redução da mortalidade das micro e pequenas empresas através de um instrumento de crédito específico para esse segmento. In: SEGET Simpósio de Excelência em Gestão e Tecnologia, 2. 2005, Resende. Anais... Resende, 2005.

OLIVEIRA JUNIOR, Z. G.; CASTRO, D. S. P. Gestão do conhecimento em arranjos produtivos locais estudo de caso do pólo brasileiro de cosmético em diadema. In.: EnANPAD - Encontro da Associação Nacional de Pós-Graduação e Pesquisa em Administração, 32. 2008. Rio de Janeiro. Anais... Rio de Janeiro, 2008.

OURO FILHO, Abimael Magno do. Análise dos Fatores Condicionantes da Desarticulação na Cooperação em um Arranjo Produtivo Local: o caso de Tobias Barreto/SE, 2013. $124 \mathrm{f}$. Dissertação (Mestrado) - Programa de Pós-Graduação e Pesquisa em Administração, Universidade Federal de Sergipe, São Cristóvão, 2013.

PASSOS, A. F.; PAIVA, L. H.; GALIZA, M.; COSTANZI, R. N. Focalização, sustentabilidade e marco legal: uma revisão de literatura de microfinanças. Mercado de trabalho - conjuntura e análise. Instituto de Pesquisa Econômica Aplicada - Ipea, Ministério do Trabalho e Emprego - MTE e Associação Nacional dos Centros de Pós-Graduação em Economia, Rio de Janeiro, n. 18, 2002.

QUANDT, C. O. Redes de cooperação e inovação localizada: estudo de caso de um arranjo produtivo local. RAI - Revista de Administração e Inovação, São Paulo, v. 9, n. 1, p.141- 66, jan./mar., 2012.

QUICK, Bruno. Brasil: um Gigante Sustentado por Micro e Pequenos. Revista Sebrae, ago/set 2003.

SANTOS, V. S. O Microcrédito como Mecanismo de Fomento para o Desenvolvimento Socioeconômico. Dissertação de Mestre no Curso de Mestrado em Gestão e Desenvolvimento Regional do Departamento de Economia, Contabilidade e Administração da Universidade de Taubaté, 2006. 
SANTOS, A.G.; DINIZ, E.J.; BARBOSA, E.K. Arranjos produtivos locais, política industrial e desenvolvimento. In: Arranjos produtivos locais e desenvolvimento. BNDS. 2006. Disponível em <www.bnds.gov.br>. Acesso em: 04 jun. 2012.

SELA, V. M. F. SELA, E. R. COSTA, S. C. da. A Importância do Microcrédito para o Desenvolvimento Econômico e Social: um estudo sobre as contribuições proporcionadas pelo Banco do Povo de Maringá aos tomadores de microcrédito. In.: EnANPAD - Encontro da Associação Nacional de Pós-Graduação e Pesquisa em Administração, 30. 2006. Salvador. Anais... Salvador, 2006.

SEBRAE - Serviço Brasileiro de Apoio às Micro e Pequenas Empresas. o que é e quem pode acessar o microcrédito. Disponível em: <http://www.sebrae.com.br/setor/servicos/osetor/acesso-a-servicos-financeiros/microcredito/integra_bia/ident_unico/450>. Acesso em 12 jul. 2012a.

SEBRAE - Serviço Brasileiro de Apoio às Micro e Pequenas Empresas. Critérios e conceitos para classificação de empresas. Disponível em: http://www.sebrae.com.br/uf/goias/indicadores-das-mpe/classificacaoempresarial/integra_bia/ident_unico/97. Acesso em: 26 jul. 2012b.

SEBRAE - Serviço Brasileiro de Apoio às Micro e Pequenas Empresas. Taxa de Sobrevivência das Empresas no Brasil. Brasília: SEBRAE, 2011.

SEBRAE - Serviço Brasileiro de Apoio às Micro e Pequenas Empresas. Fatores condicionantes e taxas de sobrevivência e mortalidade das micro e pequenas empresas no Brasil, 20032005. Brasília: SEBRAE, 2007.

SEBRAE - Serviço Brasileiro de Apoio às Micro e Pequenas Empresas. DIEESE. Anuário do trabalho na micro e pequena empresa. Brasília: SEBRAE, 2009.

SILVEIRA FILHO, J.A. Microcrédito na região metropolitana do Recife: experiência empreendedora do Ceape. Dissertação de Mestrado em Economia - Universidade Federal de Pernambuco. Recife: UFPE, 2005.

SOUZA, K. J. F.; GOMES, M. L. B. Fatores facilitadores e que dificultam a formação para redes de cooperação produtiva: estudo de casos em pequenas empresas do setor metal-mecânico. In.: SIMPEP - Simpósio de Engenharia de Produção, 12. 2005. Bauru. Anais... Bauru, 2005.

TEIXEIRA, R. M.; BARBOSA, J. D. Pequenas e medias indústrias de Sergipe: diagnóstico de gestão. SEBRAE: Aracaju, 2002.

VERSCHOORE, J. R. S. Redes de cooperação interorganizacionais : a identificação de atributos e benefícios para um modelo de gestão . Tese (doutorado) - Programa de Pós-Graduação em Administração, Porto Alegre, Universidade Federal do Rio Grande do Sul, 2006.

ZICA, R. M. F.; MARTINS, H. C.; CHAVEZ, A. F. B. Dificuldades e Perspectivas de Acesso ao Sistema Financeiro Nacional pelas Micro e Pequenas Empresas. Revista de Administração Pública, da Fundação Getúlio Vargas, n. 1, v. 42, p. 1-16, mar. 2008.

YIN, R. K. Estudo de caso: planejamento e métodos. 3ํㅜ ed. Porto Alegre: Bookman, 2005.

YUNUS, Muhammad. 0 Banqueiro dos Pobres. 1a ed. São Paulo, Editora Ática, 2002. 